\title{
Germ Cell Tumor's Survival Rate in Young Patients
}

\author{
Nafiseh Mortazavi, ${ }^{1}$ Parvin Mahzooni, ${ }^{2}$ Diana Taheri, ${ }^{2}$ Mahshid Jalilian, ${ }^{3}$ and Kambiz Novin ${ }^{4,}$ \\ ${ }^{1}$ Department of Pathology, Shahid Beheshti University of Medical Sciences, Tehran, IR Iran \\ Department of Pathology, Shahid Beheshti University of Medical Sciences, Tehran,
2 Department of Pathology, Isfahan University of Medical Sciences, Isfahan, IR Iran \\ 2 Department of Pathology, Isfahan University of Medical Sciences, Isfahan, IR Iran
3 Department of Radiation Oncology, Isfahan University of Medical Sciences, Isfahan, IR Iran \\ 3 Department of Radiation Oncology, Isfahan University of Medical Sciences, Isfahan, IR Iran
${ }^{4}$ Department of Radiation Oncology, Shahid Beheshti University of Medical Sciences, Tehran, IR Iran \\ ${ }^{*}$ Corresponding author: Kambiz Novin, Department of Radiation Oncology, Shahid Beheshti University of Medical Sciences, Tehran, IR Iran. Tel: +98-2173432621, Fax: +98-2177552056, \\ E-mail:kamnar2005@yahoo.com
}

Received: July 7, 2015; Accepted: July 11, 2015

\begin{abstract}
Background: Germ cell tumors are neoplasms that originate from multi potential germ cells and can be intra or extra gonadal. According to pathologic classification, they have different subtypes. They account for $3 \%$ of pediatric malignancies and most commonly happen in children before the age of 15 years old. Epidemiologic evidence about pediatric germ cell tumors is scant in our region.

Objectives: The aim of current study was to determine demographic characteristics, recurrence and survival rate of germ cell tumor patients under the age of 21 years.

Patients and Methods: During a 10-year period (1996 - 2006), 106 patients under the age of 21 years suffering from germ cell tumor were admitted to our centers. We extracted the data needed for our study from patients' medical records in the hospitals.

Results: Thirty seven boys and 69 girls with a mean age of $8.4 \pm 7.8$ years were included. Most tumors were diagnosed before the age of one year (37\%). The most common pathologic subtype was mature teratoma (44\%). Ovary (35\%) was the most common primary site. Surgery plus chemotherapy were used to treat 54 patients and BEP was the most common chemotherapy regimen. Metastasis and recurrent tumor were seen in $22 \%$ and $8 \%$ of cases, respectively. Four-year overall survival was $89 \%$.

Conclusions: Our study showed that demographic characteristics of GCT patients in our population are similar to patients of other geographic regions in the world. Primary tumor site, histologic subtype and metastasis were significant prognostic factors for survival.
\end{abstract}

Keywords: Germ Cell Tumor; Survival; Neoplasms

\section{Background}

Germ cell tumors (GCTs) are benign or malignant neoplasms of heterogeneous nature that can occur in gonadal and midline extra gonadal sites (1). They account for $3 \%$ of pediatric malignancies and most commonly happen in children before the age of 15 years. GCTs are more common in female than male (boy: girl ratio; 0.8:1) (2). GCTs originate from the multi potential germ cells which migrate during embryogenesis along the midline of the body to the gonadal sites. The tumors in extra gonadal locations are believed to originate from germ cells that failed to migrate to the gonads (3-6). Although the rate of malignant GCTs differs by age and location, generally about $20 \%$ of them are malignant $(7,8)$. Pediatric GCTs are distinguishable from their adult counterparts by several features. In children, about $50 \%$ of tumors are extra gonadal, whereas in adults this rate is only $10 \%$. Yolk sac tumor is the most common histologic subtype compared with seminoma/dysgerminoma in adults. Since introduction of platinum based chemotherapy in the 1980s, survival of these tumors has improved dramatically so that five-year survival rates of $90 \%$ have been reported. Even, better survival has been observed for gonadal in comparison with extra gonadal tumors (9). GCTs are classified into two groups including seminomas, comprised of the seminomas of the testis and dysgerminomas of the ovary, and nonseminomas. Nonseminomatous GCTs include histologic subtypes of yolk sac tumors, teratomas, embryonal carcinomas, and choriocarcinomas. Teratomas are the most common GCT in the ovary and extragonadal locations (10).

\section{Objectives}

In recent study, we investigated the demographic characteristics, recurrence and survival rate of germ cell tumor patients under the age of 21 years admitted to our oncology centers in Iran.

\section{Patients and Methods}

Patients with the diagnosis of GCTs admitted between 1996 and 2006 to our cancer centers were investigated. All patients under the age of 21 years with biopsy proven germ cell tumors of any primary sites that their hospital profiles were available and contained pathology report included in the study. All medical files of the included patients were investigated and with a previously prepared

Copyright (C) 2015, Iranian Journal of Cancer Prevention. This is an open-access article distributed under the terms of the Creative Commons Attribution-NonCommercial 4.0 International License (http://creativecommons.org/licenses/by-nc/4.0/) which permits copy and redistribute the material just in noncommercial usages, provided the original work is properly cited. 
fact sheet the following data were collected and analyzed: age, sex, date of diagnosis, primary tumor site, histologic subtype of the primary tumor, localization of metastatic sites at diagnosis, recurrence date and site (if any) and date of death (if any). We had no missing data regarding demographic information like sex and age and also tumor characteristics like primary site and histology, as all these data were available in the pathology reports and observation notes.

\subsection{Statistics}

Patients' baseline characteristics, disease and treatment factors were summarized using descriptive statistics. The categorical parameters were compared using two-sided Pearson's $\chi^{2}$ test or Fisher's exact test, as appropriate. If the patient was alive, his/her follow up period was considered from the date of initial pathologic diagnosis to the date of last recorded visit. If the patient was recorded as dead, this period was considered from the date of initial pathologic diagnosis to the date of recorded death. The event free survival (EFS) was defined as survival without progression, recurrence, and death. The overall survival (OS) time was defined as the period from the diagnosis until death of any cause or until the date of the last follow-up, at which data point was censored. All summary statistics on time-to-event variables were calculated according to the Kaplan- Meier method. SPSS software (version 21.0) was used for statistical analysis. A P value $<0.05$ was considered significant.

\subsection{Ethics}

This retrospective study was approved by the local scientific and ethical committee.

\section{Results}

\subsection{Patient Characteristics}

During a period of ten years, a total of 106 patients (37 boys, 69 girls, the mean age: $8.4 \pm 7.8$ years) with inclusion criteria of the study were investigated. Age distribution showed a bimodal pattern with significant predominance in the age groups of less than 1 year and 10 - 19 years (37\% and $35 \%$ of total patients respectively). Statistical analysis showed that the mean age of boys and girls in this study had not significant difference $(\mathrm{P}=0.77)$. Patients' characteristics are detailed in the Table 1.

\begin{tabular}{|c|c|c|c|c|c|c|c|c|}
\hline \multirow[t]{2}{*}{ Characteristic } & \multicolumn{5}{|c|}{ Tumor Site } & \multirow[t]{2}{*}{ Unknown } & \multirow[t]{2}{*}{ Total } & \multirow[t]{2}{*}{ P Value } \\
\hline & Testis & Ovary & Head and Neck & Sacrococcyx & Other Sites & & & \\
\hline Gender & & & & & & & & $<0.001$ \\
\hline Male & $17(100)$ & - & $6(75)$ & $11(37)$ & $2(22)$ & $1(20)$ & $37(35)$ & \\
\hline Female & - & $37(100)$ & $2(25)$ & $19(63)$ & $7(78)$ & $4(80)$ & $69(65)$ & \\
\hline Age, y & & & & & & & & $<0.001$ \\
\hline$<1$ & $3(18)$ & $2(5)$ & & $28(93)$ & $6(27)$ & & $39(37)$ & \\
\hline $1-9$ & $1(6)$ & $4(11)$ & & $2(7)$ & $13(59)$ & & $20(19)$ & \\
\hline $10-19$ & $7(41)$ & $27(73)$ & & - & $3(14)$ & & $37(35)$ & \\
\hline$\geq 20$ & $6(35)$ & $4(11)$ & & - & - & & $10(9)$ & \\
\hline Histology & & & & & & & & $<0.001$ \\
\hline MT & - & $16(43)$ & & $24(80)$ & $7(31)$ & & $47(44)$ & \\
\hline IT & $2(12)$ & $1(3)$ & & $5(17)$ & $3(14)$ & & $11(10)$ & \\
\hline Sem/Dysg & $1(5)$ & $12(32)$ & & - & - & & $13(12)$ & \\
\hline $\mathrm{EC}$ & $6(35)$ & - & & - & - & & $6(6)$ & \\
\hline YT & $3(18)$ & $4(11)$ & & $1(3)$ & $9(41)$ & & $17(16)$ & \\
\hline $\mathrm{CC}$ & $2(12)$ & - & & - & - & & $2(2)$ & \\
\hline GE & - & - & & - & $3(14)$ & & $3(3)$ & \\
\hline Mixed GCT & $3(18)$ & $4(11)$ & & - & - & & $7(7)$ & \\
\hline
\end{tabular}

a Abbreviations: CC, choriocarcinoma; EC, embryonal arcinoma; GCT, germ cell tumor; GE, germinoma; IT, immature teratoma; MT, mature teratoma; Sem/Dysg, seminoma/dysgerminoma; YT, yolk sac tumor.

b Data are presented as No. (\%). 


\subsection{Disease Characteristics}

The most common primary site of GCTs in our study was ovary (37 patients or 35\% of total). Sacrococcyx and testis were the subsequent most primaries with $28 \%$ and $16 \%$ of total patients respectively. Out of 37 male with GCTs, 11 cases (30\%) occurred in sacrococcyx and this values for 69 female GCTs were 19 and 27.5\%, respectively. Regardless of ovarian and testicular GCTs that are sex specific, statistical analysis showed the sex distribution of other primary sites also had significant differences $(\mathrm{P}<0.001)$. Table 1 show that $93 \%$ of sacrococcygeal cases were diagnosed before the age of 1 year. Diagnosis of cases with testicular and ovarian primaries were mostly after the age of 10 years old ( $76 \%$ and $84 \%$ respectively). Statistical analysis again proved that primary site distribution is significantly different according to the age at diagnosis $(\mathrm{P}<0.001)$. Teratoma was the most common GCT subtype in our study (54\% of total patients) and yolk sac tumor was the second most common one (16\%). Teratoma most commonly happened in sacrococcygeal site. Embryonal carcinoma was the most common diagnosis of primary testicular GCTs but never occurred in ovary. As shown by statistical analysis, there were significant differences between histologic subtypes distribution according to sex and also primary tumor site $(\mathrm{P}=0.008$ and $\mathrm{P}<0.001$, respectively). Metastasis occurred in 23 cases (8 males and 15 females) at diagnosis and retroperitoneal lymph nodes (RPLN) were the most common metastatic site (35\%). Abdomen (30\%) and lung (22\%) were the second and third respectively. Sex was not a significant predictor of metastasis $(\mathrm{P}=0.99)$. The mean age at diagnosis was 12.3 years and 7.1 years old for metastatic and non-metastatic cases respectively and this difference was statistically significant $(\mathrm{P}=0.005)$.

\subsection{Treatment Characteristics}

Surgery alone was done for 50 patients also 54 patients received combination of chemotherapy and surgery. In two cases radiotherapy alone or in combination with surgery was administered. Mature teratoma was the most common GCT for which surgery alone was done (86\% of all surgery only cases). BEP (Bleomycin plus Etoposide plus Cisplatin) was the most common chemotherapy regimen administered for the patients (71\% of all chemotherapy cases).

\subsection{Survival}

Five patients had no recorded data about follow up after initial diagnosis and for 101 remaining patients the range of recorded follow ups were 3 to 138 months. With a median follow-up period of 50 months, EFS and OS was $92 \%$ and $89 \%$ respectively. Out of 8 recurrent cases, $12.5 \%$ happened in males and $87.5 \%$ in females but this difference was not significant $(\mathrm{P}=0.26)$. More recurrences occurred for patients who received chemotherapy plus surgery compared with surgery alone but again the difference was not statis- tically significant $(\mathrm{P}=0.06)$. Recurrence and death rates according to disease and treatment characteristics are shown in Table 2. More deaths happened when yolk sac tumor was the histologic subtype and sacrococcyx was the primary tumor site and these differences were statistically significant $(\mathrm{P}=0.04$ and $\mathrm{P}<0.05$ respectively). Mean EFS according to presence and absence of metastasis were 43.5 months and 49 months $(\mathrm{P}=0.04)$. For overall survival rate these values were 39 months and 48 months respectively $(\mathrm{P}<0.05)$. Figures 1 and 2 shows these differences of EFSs and OSs between the two groups.

\begin{tabular}{|c|c|c|c|c|}
\hline Characteristic & Recurrence & P Value & Death & P Value \\
\hline Gender & & 0.26 & & 0.21 \\
\hline Male & $1(12.5)$ & & $2(17)$ & \\
\hline Female & $7(87.5)$ & & $10(83)$ & \\
\hline Site of Recurrence & & NA & & \\
\hline Ovary & $2(25)$ & & & \\
\hline Sacrococcyx & $3(37.5)$ & & & \\
\hline Other extragonadal & $3(37.5)$ & & & \\
\hline Histology & & NA & & 0.04 \\
\hline MT & $1(12.5)$ & & $2(16.7)$ & \\
\hline IT & $2(25)$ & & $2(16.7)$ & \\
\hline EC & $3(37.5)$ & & $2(16.7)$ & \\
\hline YT & $2(25)$ & & $4(33.2)$ & \\
\hline Mixed GCT & - & & $2(16.7)$ & \\
\hline Primary Tumor Site & & & & $<0.05$ \\
\hline Ovary & & & $3(25)$ & \\
\hline Testis & & & $2(17)$ & \\
\hline Sacrococcyx & & & $4(33)$ & \\
\hline Other & & & $3(25)$ & \\
\hline Type of Treatment & & 0.06 & & \\
\hline Surgery & $1(12.5)$ & & & \\
\hline $\begin{array}{l}\text { Surgery + } \\
\text { Chemotherapy }\end{array}$ & $7(87.5)$ & & & \\
\hline \multicolumn{5}{|c|}{$\begin{array}{l}\text { a Abbreviations: EC, embryonal arcinoma; GCT, germ cell tumor; IT, } \\
\text { immature teratoma; MT, mature teratoma; NA, not applicable; YT, yolk } \\
\text { sac tumor. } \\
\text { b Data are presented as No. (\%). }\end{array}$} \\
\hline
\end{tabular}

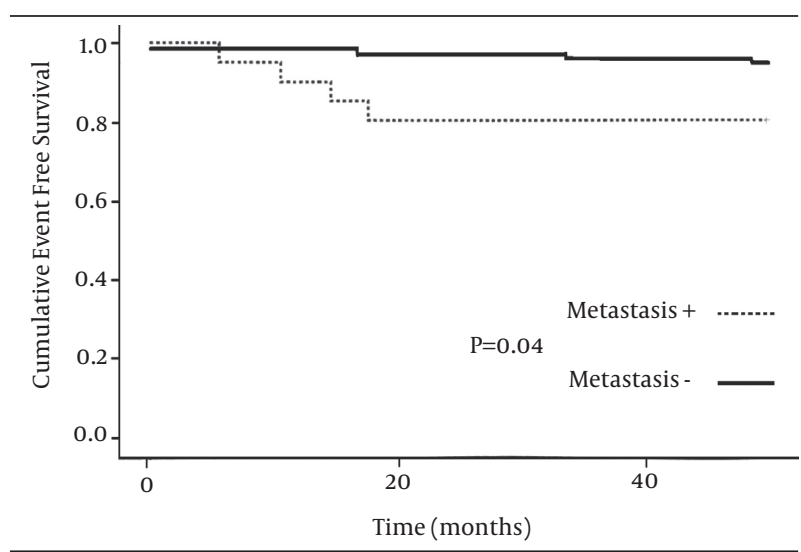

Figure 1. Kaplan Meier Estimates for Event Free Survival According to Presence or Absence of Metastasis at Presentation 
Mortazavi N et al.

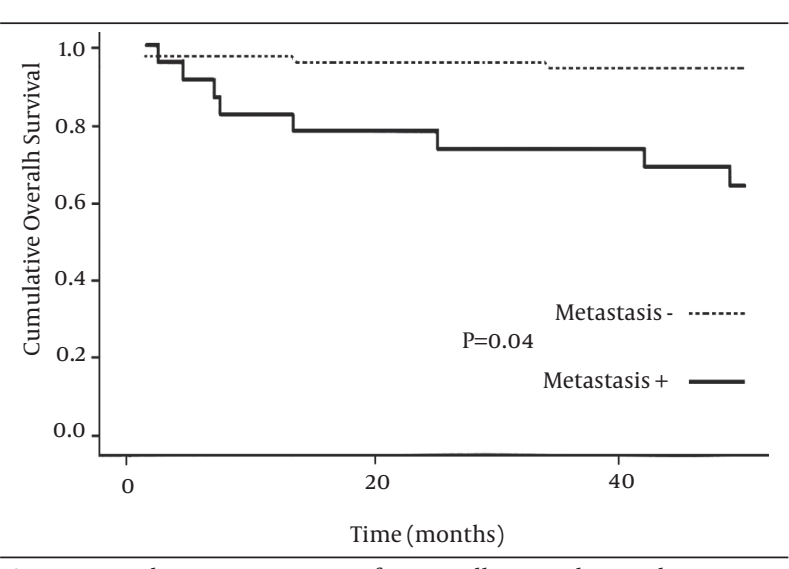

Figure 2. Kaplan Meier Estimates for Overall Survival According to Presence or Absence of Metastasis at Presentation

\section{Discussion}

Patients in our study had demographic and clinical features similar to those reported in other series, with respect to age, sex, primary tumor site and histologic subtype $(1,9,11-13)$. Sex distribution showed a female predominance with a male to female ratio of 0.5:1. This female predominance is higher than those observed in German Childhood Cancer Registry in 1987 - 2011 (11). This can partly be explained by different upper age limits in inclusion criteria of the two studies (21 years in our study compared with 14 years in German study). However, we should also consider different genetic and geographic features of the two patient populations. Our results showed a bimodal age distribution with a peak incidence during infancy and another one in adolescence. Ovary and teratoma were the most common primary site and histologic subtype in our study and these are similar to other reports. Four-year overall survival rate was $89 \%$ for all patients in our study. Although data about patients' disease stages at presentation is not available, this high survival rate is in concordance with results of some other series $(9,14)$. One explanation for these high survival rates of GCTs is the effectiveness of platinum-based chemotherapy. The recorded recurrence rate in our patient population is low (about $8 \%$ ) and EFS of $92 \%$ is much higher than other reported series (14). There are some reasons to explain that; GCTs in Italian Cooperative Study were all malignant while in our study mature teratoma comprised considerable amount of the tumors (44\%). About half of the patients in an Italian study had advanced disease at presentation. It may be attributable to probable lower disease stages of our patient population, although these data are not available now; another explanation can be irregular follow ups of our patients resulted in lower detection rate of probable recurrences. Regardless of tumor stage at presentation whose data is not available here, our recent investigation suggested three prognostic factors for poorer survival; yolk sac histology, sacrococcygeal primary site and presence of metastasis at presentation. These are in concordance with other reported series $(8,14)$.
Our results showed that demographic characteristics of GCT patients in our population are similar to patients of other geographic regions in the world and high survival rates can be expected in the case of these rare tumors.

\section{Acknowledgements}

We sincerely thank Ali Mehrabi for statistical consulting.

\section{Authors' Contributions}

Study conception and design: Nafiseh Mortazavi, Parvin Mahzooni; Acquisition of data: Nafiseh Mortazavi, Kambiz Novin; Analysis and interpretation of data: Kambiz Novin, Parvin Mahzooni, Diana Taheri, Mahshid Jalilian; Drafting of manuscript: Kambiz Novin, Nafiseh Mortazavi; Critical revision: Diana Taheri, Mahshid Jalilian.

\section{Conflict of Interest}

The authors declare that they have no conflict of interest.

\section{Financial Disclosure}

The authors declare that they have no financial interest.

\section{References}

1. Penn A, Jenney MEM, Nicholson JC. Germ cell tumours in children and adolescents. Paediatr Child Health. 2014;24(4):148-54.

2. Kaatsch P. Epidemiology of childhood cancer. Cancer Treat Rev 2010;36(4):277-85.

3. Teilum G. Classification of endodermal sinus tumour (mesoblatoma vitellinum) and so-called "embryonal carcinoma" of the ovary. Acta Pathol Microbiol Scand. 1965;64(4):407-29.

4. Rescorla FJ. Pediatric germ cell tumors. Semin Surg Oncol. 1999;16(2):144-58.

5. Schneider DT, Schuster AE, Fritsch MK, Hu J, Olson T, Lauer S, et al. Multipoint imprinting analysis indicates a common precursor cell for gonadal and nongonadal pediatric germ cell tumors. Cancer Res. 2001;61(19):7268-76.

6. Oosterhuis JW, Stoop H, Honecker F, Looijenga LH. Why human extragonadal germ cell tumours occur in the midline of the body: old concepts, new perspectives. Int J Androl. 2007;30(4):256-63.

7. Young JJ, Ries LG, Silverberg E, Horm JW, Miller RW. Cancer incidence, survival, and mortality for children younger than age 15 years. Cancer. 1986;58(2 Suppl):598-602.

8. Gobel U, Schneider DT, Calaminus G, Haas RJ, Schmidt P, Harms D. Germ-cell tumors in childhood and adolescence. GPOH MAKEI and the MAHO study groups. Ann Oncol. 2000;11(3):263-71.

9. Poynter JN, Amatruda JF, Ross JA. Trends in incidence and survival of pediatric and adolescent patients with germ cell tumors in the United States, 1975 to 2006. Cancer. 2010;116(20):4882-91.

10. Cushing B. Germ Cell Tumors. In: Pizzo P, Poplack D, editors. Principles and practice of pediatric oncology. 5th ed. Philadelphia: Lippincott, Williams and Wilkins; 2006.

11. Kaatsch P, Häfner C, Calaminus G, Blettner M, Tulla M. Pediatric germ cell tumors from 1987 to 2011: incidence rates, time trends, and survival. Pediatr. 2015;135(1):e136-43.

12. Murray MJ, Nicholson JC. Germ cell tumours in children and adolescents. Paediatr Child Health. 2010;20(3):109-16.

13. Arora RS, Alston RD, Eden TO, Geraci M, Birch JM. Comparative in cidence patterns and trends of gonadal and extragonadal germ cell tumors in England, 1979 to 2003. Cancer. 2012;118(17):4290-7.

14. Lo Curto M, Lumia F, Alaggio R, Cecchetto G, Almasio P, Indolfi $\mathrm{P}$, et al. Malignant germ cell tumors in childhood: results of the first Italian cooperative study "TCG 91". Med Pediatr Oncol. 2003;41(5):417-25. 